\title{
How tobacco companies ensure prime placement of their advertising and products in stores: interviews with retailers about tobacco company incentive programmes
}

\author{
E C Feighery, K M Ribisl, P I Clark, H H Haladjian
}

Tobacco Control 2003;12:184-188

See end of article for authors' affiliations

.....................

Correspondence to: Ellen Feighery, Public Health Institute, 141 Kelly Avenue, Half Moon Bay, CA 94019, USA efeighery@mac.com

Received 3 April 2002

Accepted 24 February

2003
Background: About $81 \%$ of cigarette manufacturers' marketing expenditures in the USA is spent to promote cigarette sales in stores. Relatively little is known about how these expenditures help the manufacturers achieve their marketing goals in stores. A better understanding of how tobacco companies influence the retail environment would help researchers and tobacco control activists to monitor industry presence in stores.

Objective: To describe the types of tobacco company incentive programmes offered to retailers, how these programmes impact the store environments, and possible visual indicators of retailer participation in incentive programmes.

Study design: In-depth qualitative interviews with a convenience sample of 29 tobacco retailers were conducted in 2001.

Setting: USA.

Main outcome measures: The types and requirements of retailer incentive programmes provided by tobacco companies, and how participation in a programme alters their stores.

Results: The retailers provided insights into how tobacco companies convey promotional allowances and special offers to them and how these incentives shape the retail environment. Retailers noted that tobacco companies exert substantial control over their stores by requiring placement of products in the most visible locations, and of specific amounts and types of advertising in prime locations in the store. Retailers also described how tobacco companies reduce prices by offering them volume based discounts, "buy two, get one free" specials, and "buying down" the price of existing product.

Conclusions: Tobacco companies are concentrating their marketing dollars at the point-of-sale to the extent that the store is their primary communication channel with customers. As a result, all shoppers regardless of age or smoking status are exposed to pro-smoking messages. Given the financial resources spent by tobacco companies in stores, this venue warrants closer scrutiny by researchers and tobacco control advocates.
$\mathrm{T}$ he retail store is the major communication channel between the tobacco companies and their present and future customers. The tobacco companies offer a variety of incentives to retailers to stimulate or "push" sales of their products. ${ }^{12}$ Of the record US\$9.57 billion spent by the cigarette manufacturers to market their products in 2000, the overwhelming majority of this spending occurred in retail outlets. ${ }^{3}$

Tobacco companies spent $\$ 4.26$ billion dollars or $44.5 \%$ of the total expenditures on point-of-sale advertising and promotional allowances, which include payments to retailers for prime shelf space and in-store displays as well as volume discounts and promotional price reductions (buydowns). Tobacco companies spent $\$ 3.52$ billion dollars or $36.7 \%$ of the total expenditures on retail value added items, such as gifts with purchase and multi-pack discounts. Taken together, the cigarette manufacturers spent $81.2 \%$ of their marketing dollars in stores, where the industry is relatively free of regulation.

These expenditures are intended to increase demand and to ensure a ubiquitous supply of product for the addicted customer. A 1999 statewide survey of stores in California that sell cigarettes found that they feature an average of 17 cigarette ads and promotional materials, such as display racks, posters, signs, and branded functional items (for example, clocks, shopping baskets). About $90 \%$ of all tobacco marketing materials were located within four feet $(1.3 \mathrm{~m})$ of checkout counters, the prime location in most stores. ${ }^{4}$ In a survey of stores in 42 states also conducted in 1999, 92\% had some form of tobacco point-of-purchase marketing materials. Over one quarter of the stores offered multi-pack discounts. ${ }^{5}$ The results of these two studies suggest that tobacco companies have made strategic use of retail outlets to market their products.

Little systematic data are available on retailer incentive programmes because these transactions are negotiated privately ${ }^{6}$ and are unique to each retail outlet. A small study of tobacco retailers in one California county found that tobacco companies were far more likely to offer slotting/display fees than were manufacturers of four other product types, and about two thirds of the retailers $(62.4 \%)$ received payments from tobacco companies. ${ }^{7}$ An overview of slotting fees and trade promotions provided by tobacco companies to retailers suggested that in return for financial incentives offered to retailers, the tobacco companies require a fair amount of control over product placement, advertising and pricing. ${ }^{2}$ The present study builds on prior efforts by exploring in-depth the nature and characteristics of the exchange between tobacco companies and retailers, and its subsequent effect on the store environment. Qualitative interviews were conducted with managers and owners of stores that sell tobacco to learn about how tobacco company incentive programmes impact their store environments in terms of product and ad placement and pricing strategies, and identification of possible visual markers of tobacco company incentive programmes in stores. 


\section{METHODS Sample}

In spring of 2001, in-depth telephone interviews were conducted with a convenience sample of 29 tobacco retailers in 21 US states. Respondents were identified from the Yahoo! Yellow Pages. We recruited owners or managers of independent stores, such as small groceries, convenience stores, and liquor stores. We also recruited store managers (or department managers) of retail chains, such as supermarkets, pharmacies, and franchise and non-franchise convenience stores. Respondents included 15 store managers, nine assistant or section managers, and five owners. Types of stores included: nine small grocery stores with and without gas (petrol), nine convenience stores with and without gas (petrol), five liquor stores, three chain supermarkets, two chain pharmacies, and one mass general merchandiser. Fourteen stores were independently owned, eleven were part of a chain, and four were franchises.

\section{Procedures and measures}

All interviews were conducted by the San Francisco based market research firm of Cooper Roberts Research. A script that ensured anonymity was read to retailers and consent was secured before commencing the interview. Interviews lasted 30-45 minutes, and participants were given a \$100 gift certificate as an incentive. Areas of discussion included: the types and requirements of retailer incentive programmes provided by tobacco companies, how participation in a tobacco company programme alters the store environment, and visual markers of tobacco company incentive programmes.

\section{Analysis}

The interviews were audio taped and the tapes transcribed in full for line-by-line thematic analysis. A multi-step process was used to identify the key findings from the interviews. Each of the authors reviewed the interview transcripts and major topics of interest were identified. A subset of the major topics was assigned to each author to cluster retailer comments accordingly. The author then reviewed the transcripts and identified key themes in a major topic area. These emerging themes were illustrated by verbatim anonymous quotes from the retailers. The clustered topics, themes, and comments were then reviewed and edited by all authors.

\section{RESULTS}

The results are organised into four major categories: (1) competition among tobacco companies for sales and store space; (2) descriptions of incentive programmes; (3) requirements of participation in these programmes; and (4) visual markers of tobacco company incentives in stores.

\section{Retailer perceptions of competition among the tobacco companies}

The merchants confirmed that stores are prime targets of aggressive marketing by tobacco companies. They observed that there is stiff competition as tobacco companies compete for sales. Competition is particularly intense between the two largest companies, Philip Morris and RJ Reynolds. Retailers noted that the smaller tobacco companies are at a competitive disadvantage compared to these two companies. Most of the retailers said that they take advantage of the competition by participating in several incentive programmes. Tobacco companies are sensitive to the practices of their competitors. As one company reduces the price of a pack or carton of cigarettes, another company is likely to match the promotions by reducing the prices of their own brands.

"The steam engine of the tobacco world has control of the market and sets the standards. They set standards for everything. They are the leader and everyone follows.
Everyone follows what they do whether it is advertising, pricing or promotions. Philip Morris is definitely the leader here. Whatever they come out with then RIR follows." (Manager of independent convenience store with gas)

"Most of the time Marlboro [Philip Morris] and RJR compete and not the smaller guys. If Camel [RJ Reynolds] does some advertising Marlboro does too. They drop their prices too. Occasionally Newport [Lorillard] will provide a coupon or something like that." (Owner of a convenience store with gas)

\section{Retailer descriptions of incentive programmes}

Retailers described two major mechanisms used by tobacco companies to convey promotional allowances and special offers to them. Retailers said that volume discounts and display allowances typically are included in contracts, although there is substantial variability in how they are configured. Some retailers said that buydowns (time limited price reductions or sales) were included in their contracts, whereas others noted that these were offered through inventory counts and invoices to document the sales. This section describes contracts and their usual provisions, followed by a discussion of buydowns.

\section{Contracts}

Many of the retailers reported they currently have or used to have contracts with tobacco companies. Retailers described contracts in a variety of ways so it appears that tobacco companies do not offer just one standard contract to all retailers but instead tailor the various provisions to individual stores or chains. There was consensus, though, that the companies offered volume discounts via contracts for stores meeting minimum sales volume standards. After the sales volume is determined by the average number of cartons sold, the tobacco company offers a contract to the retailer that specifies a level of payment to be made on a periodic basis (for example, discounts range from 25-90 cents per carton sold in a quarter). In return for these payments, the retailers said that they must agree to abide by specifications on placement of the product on displays and shelving units. These types of contracts were usually long term, although the volume and terms were reviewed regularly. Payments are usually made quarterly. Sometimes contracts even specified pricing. The tobacco companies tried to control where their products were placed as well as the amount of space allocated to their products in stores by offering retailers these types of deals.

"Philip Morris has contracts for different levels for different volume. More volume, the better the contract-the more money you get. Buydowns, percent of display area and placement of display are part of the contract. Some contracts last 30 days, others quarterly, still others last longer. Marlboro is the most demanding." (Independent convenience store owner)

"Some reps require contracts; they have different volume levels. The contract asks for prime advertising location in the store, near the first register or a banner outside. The store would get a payment." (Independent liquor store manager.

"They come in and say I want $45 \%$ of your space, if that is the market share they command in the area. They say, 'I will provide the rack/bin and I will pay you 35 cents a pack for a year' . . . . You have to maintain the right percentage of their product, put up signage and keep track 
of your cartons which they pay you for." (Independent convenience store manager)

"With our RJR contract, we can't sell any cartons lower than the best value of $\$ 18.14$. We can't carry cigarettes that sell for less than that. They pay quarterly for that. They give us big racks for the cartons and a pack rack. Doral also is in the carton spot by the front door. It stands on the floor and customers can pick out what they want. We can only sell cartons for $\$ 30.03$. That is the highest we can go. We purchase them for $\$ 20.14$ in the Doral brand and sell it for \$27.14." (Independent liquor store owner)

\section{Buydowns}

A common type of incentive offered by the tobacco companies is a buydown which is used to place existing inventory on sale. The buydown specifies the sale in terms of the "cents off" on each pack in the store's inventory for a defined period of time. Unlike volume discounts, the entire price reduction is passed on to the customer when a product is on buydown. In return for the opportunity to offer the sale, the retailer must use special displays and signage provided by the tobacco company. At the end of the buydown period, the retailer is reimbursed the difference between the inventory price and the reduced price. Since buydowns usually are paid after the product has been sold, the retailer essentially fronts the sale. According to our sample of retailers, these are becoming increasingly popular and may be replacing other forms of incentive programmes. Virtually all retailers who were interviewed participate in buydowns.

You get the rebate for any number of cartons bought. We don't receive that until we submit a form and our receipts. Then we receive a check for the difference. We are selling cigarettes and losing money until we are reimbursed." (Manager of independent convenience store with gas)

"They show us an invoice... It's counted as inventory off the product. It shows the amount and then the manufacturers give us a check for the difference. It decreases the cost of the goods sold. It's not volume based (it's one for one.) In order to get a buydown, you have to reduce price." (Independent grocery/liquor store owner)

"They used to do that (T-shirts, cameras, caps, etc) but with the tobacco lawsuits they don't give those out anymore . . .. They make up for that with buydowns and things like that." (Owner of independent grocery with gas)

"In our location we don't put anything on sale. We are very hardcore here meaning we are rural and don't have a lot of competition. None of my product goes on sale unless the sales rep requests a .25-cent buydown." (Manager of truck stop/franchise convenience store with gas)

The retailers reported that sales via buydowns are offered regularly and are sometimes an on-going programme. The retailers indicated that a sales promotion of at least one brand is going on all the time. Often, if one company puts a premium brand on special, another company would do the same with its premium brand. A tobacco company may offer a complete brand line on buydown (for example, all Marlboro brand extensions) or several brands at a time. The amount of money reimbursed on each carton varied widely among brands and companies. Some brands appeared to be on sale through continuous buydowns, and in other cases, different brands were rotated.

"[We] usually have a buydown going on all the time. It rotates around different brands and different companies." (Independent convenience store owner)

"It is mostly on Camels, Winston, Doral, and Value [R] Reynolds brands] - they usually give us back about \$6-7 a carton .... Camel and Winston will be on buydown 2 months on and 1 month off. Philip Morris might put its Marlboro and Basics on buydown at the same time. Kool [Brown \& Williamson] are about $\$ 3$ off and Salem [R Reynolds] \$4." (Independent liquor store manager)

\section{Requirements of participation}

In exchange for volume discounts and buydowns, retailers are expected to follow tobacco company requirements to place products and advertising in specific locations and to advertise special prices prominently.

\section{Prime product placement}

The retailers clearly described how the tobacco companies competed with each other to attain prime placement of their products in stores to obtain high consumer visibility. Aside from vying for prime placement of the display unit, they also wanted to ensure they had the best position on the displays themselves.

"The tobacco companies have the displays and they were trying to outbid each other... They are trying to get the space right behind the counter where the racks are .... They want the customer to see the cigarettes and the price right behind the cashiers." (Manager of franchise convenience store with gas)

"Bigger companies want their product at eye level. The smaller companies, Brown and Williamson, usually only offer contracts for temporary displays." (Independent convenience store co-owner)

"Philip Morris requires that they have $48 \%$ of space. Since that is what they sell nationwide. RJR doesn't specify percent of space." (Independent liquor store owner)

"They [the reps] tell us what promotions are coming up, look for out-of-date cigarettes, and check placement and percentage of their cigarette brands." (Independent grocery store owner)

Although retailers noted that competition for prime space is strong, they also observed that tobacco companies are increasingly supportive of clerk assisted sales methods. Several retailers expressed support for this shift because it reduces shoplifting.

"The manufacturer wants cigarettes behind the service counter and not self-serve and as long as you do that, they will pay you promotional money. Along with certain limitations on how the rack is set like $30 \%$ or whatever they want. To my knowledge, they actually want it behind doors or the counter so it isn't self-serve. It's to comply with legislation. I didn't argue because of shoplifting. . . The way the manufacturers have been going 
is a positive direction. Our inventory is more protected (from shoplifters)." (Independent convenience store owner)

Prominent placement of ads.

Incentive agreements also require prominent placement of signs. Many of the retailers claimed that tobacco companies stipulate how the store is supposed to advertise their products. Retailers are instructed to place signs in prime places like on product shelving and register/counter space. They described their experience with the placement of signs in almost every section of their store.

"They send a diagram that shows where the signs should go." (Franchise convenience store manager)

"I have them at the front window and door, places like that. I put signs on the special priced cigarettes on the shelf. . . They are to be put on a stand and out in the road. . . Each sign you can use in different ways. They come with double stickers, so it can be seen on both sides of the door. For a promotion, I would put up about 5 signs and they vary in size. You would see a sign that says like two for one price or one that says buy one get one free. We advertise the current lowest price in the store. Each sign will have its own logo. I clearly put what brand it is." (Owner of independent convenience store with gas)

Visual markers of tobacco company incentives in stores According to the retailers, stores that participate in tobacco company incentive programmes look different from those that do not. The retailers observed that clearly marked shelving units and displays, products placed in prime locations, discounted prices (with signs for specials or sales), and multiple signs in the same store indicate that a store is participating in an incentive programme. Retailers were asked whether and how they could tell if a store participated in a programme.

\begin{abstract}
"Yes. Just by what is on sale . ... I would see what they have price-wise going on compared to what we have. You can tell from the racks and the displays out what is on promotion ... the shelf display on top of the counter. You would see the signage all over the counter area. It would be like a logo with buy one get one free and brand. I would assume just a price poster would be their regular price." (Assistant manager of a chain convenience store with gas)
\end{abstract}

"Just signs and stickers, coupons, buy 2 get one free. Can't put on sale without a deal . . .. It's pretty obvious since the brand name is on there and you know who the manufacturer is. (Independent convenience store manager)

"If (you) don't get incentives, it's obvious because everything will be full price. The cigarettes would be buried someplace where you can't see them." (Independent liqvor store manager)

Advertisements indicating "special" prices usually reflected incentive agreement reductions. The retailers said that they are usually required to display ads for these promotions.

"When I run promotions I put a cardboard sign in the window. I have a sign on the display rack. There are price signs on there also. I have a Camel sign and Winston and American Spirit [RJ Reynolds]. They are little signs on there with the logo." (Independent liquor store owner)

\section{What this paper adds}

Tobacco companies spend about $81 \%$ of their marketing dollars on retailer incentives and product specials in the retail outlet to secure prime placement of their products and ads, and to price their brands competitively. It is estimated that about two thirds of tobacco retailers participate in at least one type of tobacco company incentive programme.

This is the first qualitative study of retailer descriptions tobacco company incentive programmes. Tobacco retailers provided in-depth information describing the types of incentive programmes that are offered by tobacco companies, how these incentive programmes function, and how these programmes affect the store environment. The perspective of tobacco retailers on these topics has not been featured in past studies. Information from this study will help guide future research and policy efforts in the area of point-of-sale marketing.

"You get the reduced price signs. They would be around the registers and cigarette area. They vary in size, it depends on what you want to do." (Independent convenience store manager)

\section{DISCUSSION}

The purpose of this paper was to describe the experiences of tobacco retailers with tobacco company incentive programmes, how these programmes impact their store environments, and possible visual indicators of retailer participation in incentive programmes. The interviews with retailers provided insights into how tobacco companies convey promotional allowances and special offers to retailers and how these incentives shape the retail environment. The retailers demonstrated a high level of familiarity with these topics and there was remarkable consistency in their responses. Clearly, the financial inducements provided to retailers by tobacco companies help to increase their profits from cigarette sales, however, they come with strings attached. Tobacco companies exert substantial control over the retail environment by requiring retailers to place their products in the most visible locations and to place specific amounts and types of advertising in certain locations in the store. The retailers identified visual markers of retailer participation in incentive programmes, and the most obvious one was branded signage that advertised prices and sales. Other markers included the placement of company brands on ads and product displays in prominent locations such as the counter area.

The 1998 Master Settlement Agreement (MSA) between tobacco companies and state attorneys general eliminated the use of many of the traditional forms of advertising the tobacco companies had been using, such as billboard and transit advertising, and it restricted sponsorships. ${ }^{8}$ The retail outlet, a venue that already had been growing as an important communication channel for tobacco companies, was left relatively unregulated by the MSA. Since the adoption of the MSA, significant increases in the amount of tobacco advertising and sales promotional activities have been observed at retail outlets. ' One advertising trade publication noted: "marketing restrictions continue to tighten, leaving fewer ad options available to the $\$ 50.1$ billion (tobacco) industry and each player scrapping harder for sacred shelf space and pointof-sale signage in store - where the vast majority of tobacco marketing dollars are spent." ${ }^{\prime 10}$ The retailers in this study confirmed that competition is fierce among tobacco companies and that Phillip Morris currently dominates the retail environment. It is clear from these interviews that tobacco companies offer, and most retailers accept, a wide variety of incentive programmes to ensure good placement of their products and advertising in prominent places in stores. 
The retailers in this study described several strategies used by tobacco companies to drive down prices including volume based discounts, buydowns, and special offers such as multi-pack discounts. It seems contradictory that the tobacco companies would have raised cigarette prices five times from 1991 to 2001, ${ }^{11}$ and then turned around and offered an array of programmes to reduce cigarette prices. Perhaps, tobacco companies may be using these strategies to soften the immediate impact of these increases ${ }^{12}$ or to protect their market share against deep discount brands. ${ }^{13}$ Another reason may be that these strategies allow the companies to have greater control over the advertising, pricing, and placement of cigarettes in retail outlets than if they had simply lowered the wholesale price of cigarettes. For instance, the companies would not have been able to ensure that the full price reduction would be passed along to the consumer as with a buydown, and the merchant would not have been obligated to display signage and promotional materials for the special prices. Finally, there may be accounting or tax advantages related to these strategies that are not yet fully understood.

The retailers' insights into tobacco company marketing strategies provide useful information to community activists and local tobacco control programmes. The visual markers identified by the retailers may provide guidance about how to assess tobacco marketing in stores. The amount and placement of ads outside the stores, the amount and placement of ads and product displays around the counters inside the stores, and cigarette brand prices all may indicate that the retailer is participating in incentive programmes. However, further investigation into reliable markers is warranted. It also is important to understand that tobacco company incentive programmes are indeed an exchange that occurs between the companies and retailers. Retailers gain financially from these incentive programmes in exchange for tobacco company control over tobacco marketing in their stores. This mutually beneficial arrangement may pose a serious barrier to achieving voluntary reductions in tobacco marketing in store environments.

Tobacco companies are concentrating their marketing dollars at the point-of-sale to the extent that the store has become their primary communication channel with smokers and non-smokers alike. The store environment serves to expose all shoppers regardless of age or smoking status to pro-smoking messages, to project powerful cues to smoke, and to stimulate cigarette purchases. ${ }^{14}{ }^{15}$ Given the financial resources being spent in stores by tobacco companies for these purposes, it is surprising that this venue has received relatively little attention from researchers, community activists, and policy makers. Because stores provide such a broad reach, closer examination of tobacco marketing practices in this venue and its resulting impact on consumers is warranted.

\section{ACKNOWLEDGEMENTS}

This study was supported by a grant (5 ROl CA86232) from the National Cancer Institute, under the Community and State Initiative of the Tobacco Control Research Branch. Its contents are solely the responsibility of the authors and do not necessarily represent the official view of the National Cancer Institute.

\section{Authors' affiliations}

E C Feighery, H H Haladjian, Public Health Institute, Berkeley, California, USA

K M Ribisl, Department of Health Behavior and Health Education, School of Public Health, University of North Carolina at Chapel Hill, Chapel Hill, North Carolina, USA

P I Clark, Battelle Centers for Public Health Research and Evaluation, Baltimore, Maryland, USA

\section{REFERENCES}

1 Belch GE, B.M., Introduction to advertising and promotion: an integrated marketing communications perspective. Boston: Irwin, 1995

2 Bloom P. Role of slotting fees and trade promotions in shaping how tobacco is marketed in retail stores. Tobacco Control 2001:10:340-4.

3 Federal Trade Commission, Report to Congress for 2000 pursuant to the Federal Cigarette Labeling and Advertising Act. Washington DC: US Federal Trade Commission, 2002.

4 Feighery EC, Ribisl KM, Schleicher NC, et al. Cigarette advertising and promotional strategies in retail outlets: results of a statewide survey in California. Tobacco Control 2001;10:184-8.

5 Terry-McElrath YM, Wakefield MA, Giovino GA, et al. Point-of-purchase tobacco environments and variation by store type. MMWR Morb Mortal Wkly Rep 2002;51:184-7.

6 Sullivan $M$. Slotting allowances and the market for new products. Journal of Law and Economics 1997;40:461-93

7 Feighery EC, Ribisl KM, Achabal DD, et al. Retail trade incentives: how tobacco industry practices compare with those of other industries. Am J Public Health 1999:89:1564-6.

8 Anon. Master Settlement Agreement. National Association of Attorneys General, 1998. http://www.naag.org/tobacco/

9 Wakefield MA, Terry-McElrath YM, Chaloupka FJ, et al. Tobacco industry marketing at point of purchase after the 1998 MSA billboard advertising ban. Am J Public Health 2002;92:937-40.

10 Dipasquale C. Store wars. Advertising Age 2002:73(2):4, 18,20,22

11 Beirne M. Big tobacco gets tough. Brandweek 2001;29-30,32,34.

12 Chaloupka FJ, Cummings KM, Morley CP, et al. Tax, price and cigarette smoking: evidence from the tobacco documents and implications for tobacco company marketing strategies. Tobacco Control 2002;11 (suppl I):i62-72.

13 Dipasquale C. Call it 'Marlboro Thursday', PM to spend $\$ 650$ mil on Q4 price promotions. Advertising Age 2002;1,60.

14 Warner KE. Selling smoke: cigarette advertising and public health. Washington DC: American Public Health Association, 1986.

15 Rogers T, Feighery EC, Tencati EM, et al. Community mobilization to reduce point-of-purchase advertising of tobacco products. Health Educ $Q$ 1995;22:427-42. 